\title{
HUBUNGAN EFEK SAMPING DENGAN KECEMASAN AKSEPTOR KB SUNTIK 3 BULAN
}

\section{RELATIONSHIP OF SIDE EFFECTS WITH ANXIETY OF INJECTABLE BIRTH CONTROL ACCEPTORS 3 MONTHS}

\author{
${ }^{1 *}$ Jujuren Sitepu, ${ }^{2}$ Anwar Pasaribu \\ ${ }^{1 *}$ Jurusan Kebidanan Politeknik Kesehatan Kemenkes Medan \\ ${ }^{2}$ Puskesmas Kota Barat, Kota Gorontalo
}

Kontak koresponden: sitepujujuren@gmail.com

\begin{abstract}
ABSTRAK
Cakupan akseptor KB suntik 3 bulan di Indonesia hingga saat ini mengalami penurunan, sehingga mempengaruhi keberhasilan program $\mathrm{KB}$ nasional. Efek samping menjadi faktor penyebab akseptor dalam memilih metode kontrasepsi KB suntik 3 bulan. Penelitian ini bertujuan untuk mengetahui hubungan efek samping dengan tingkat kecemasan akseptor KB suntik 3 bulan di Puskesmas Bulango Selatan. Penelitian menggunakan metode observasional analitik dengan pendekatan cross sectional study. Populasi adalah seluruh akseptor KB suntik 3 bulan sebanyak 81 orang dan sampel sebanyak 75 orang diperoleh melalui teknik purposive sampling. Teknik pengumpulan data dilakukan dengan wawancara menggunakan kuesioner dan dianalisis menggunakan uji pearson chi-square. Hasil penelitian ini menunjukkan bahwa paling banyak akseptor KB suntik 3 bulan dengan tidak memiliki efek samping (73.3\%), dan tingkat kecemasan ringan $(44.0 \%)$. Terdapat hubungan yang signifikan antara efek samping dan tingkat kecemasan akseptor KB suntik 3 bulan di Puskesmas Bulango Selatan ( $\mathrm{p}=0.001)$. Disarankan agar ibu lebih mengetahui informasi tentang alat kontrasepsi KB suntik 3 bulan guna dalam menekan jumlah pertumbuhan penduduk dan berperan penting dalam program KB.
\end{abstract}

Kata Kunci: efek samping; kecemasan; KB suntik

\section{ABSTRACT}

The coverage of acceptors for 3-month injections in Indonesia has decreased, thus affecting the success of the national family planning program. Side effects are a factor that causes acceptors to choose the 3-month injectable contraceptive method. This study aims to determine the relationship of side effects with the level of anxiety of 3 month injection family planning acceptors at the South Bulango Health Center. The study used an analytic observational method with a cross sectional study approach. The population is all acceptors of 3-month injection KB as many as 81 people and a sample of 75 people obtained through purposive sampling technique. The data collection technique was conducted by interview using a questionnaire and analyzed using the Pearson chi-square test. The results of this study indicate that the most acceptors of 3-month injections with no side effects (73.3\%), and mild anxiety levels (44.0\%). There was a significant relationship between side effects and anxiety levels of 3-month injection family planning acceptors at the South Bulango Health Center $(p=0.001)$. It is recommended that mothers know more about information about 3-month injectable contraceptives in order to suppress population growth and play an important role in family planning programs. 
Keywords: side effects; anxiety; KB injection

\section{Pendahuluan}

Gerakan Keluarga Berencana (KB) di Indonesia telah menjadi contoh bagaimana negara berpenduduk terbesar keempat di dunia dengan jumlah penduduk 259 juta jiwa dapat mengendalikan dan menerima Gerakan keluarga berencana sebagai salah satu bentuk pembangunan keluarga yang lebih dapat dikendalikan untuk mencapai kesejahteraan. Keluarga berencana adalah tindakan yang membantu individu atau pasangan suami-istri untuk mengatur interval diantara kelahiran, menentukan jumlah anak dalam keluarga, serta mendapatkan kelahiran yang memang diinginkan (Rahmidini et al., 2020; Sinurat \& Pinem, 2017). Hal ini dilakukan untuk mendapatkan keluarga yang sejahtera.

Angka penggunaan kontrasepsi tertinggi adalah Suntik 63,71\%, pil 17,24\%, Intra Uterine Device (IUD) 7,35\%, Kondom 1,24\%, Implan 7,2\%, MOW (Metode Operasi Wanita) 2,76\%, Metode Operasi Pria (MOP) 0,5\%. Berdasarkan data tersebut didapatkan masih rendahnya penggunaan kontrasepsi jangka panjang dikarenakan pengetahuan masyarakat yang masih rendah tentang kelebihan metode kontrasepsi jangka panjang dan keterbatasan jumlah tenaga terlatih serta sarana yang ada. Sementara itu, cakupan akseptor KB aktif di Indonesia pada tahun 2018 sebesar 36.306 .662 (74,80\%), dengan jumlah Pasangan Usia Subur (PUS) sebesar 48.536.690, dan hampir separuhnya (47,96\%) menggunakan metode kontrasepsi suntik (Kemenkes RI, 2018; Kusumawardani \& Machfudloh, 2021).

Penggunaan Akseptor KB Suntik 3 Bulan di Provinsi Gorontalo pada 3 tahun terakhir yaitu tahun 2018 berjumlah 68.634 (40,17\%), tahun 2019 berjumlah 66.657 (43,70\%), dan tahun 2020 berjumlah 67.987 (44,64\%) . Berdasarkan data Dinas Kesehatan Kabupaten Bone Bolango, dalam penggunaan Akseptor KB Suntik 3 Bulan mengalami penurunan disetiap tahunnya yaitu pada tahun 2018 Akseptor KB suntik berjumlah 8291 pengguna (32,2\%), tahun 2019 Akseptor KB suntik berjumlah 7202 pengguna $(31,4 \%)$ dan pada tahun 2020 Akseptor KB suntik 6310 pengguna $(30,7 \%)$. Sehingga dari data tersebut menunjukan bahwa di Dinas Kesehatan kabupaten Bone Bolango di tiga tahun terakhir mengalami penurunan dalam penggunaan Akseptor KB Suntik 3 Bulan. Berdasarkan data Puskesmas Bulango Selatan pada tahun 2020, menyatakan bahwa akseptor KB Suntik 3 Bulan pada tahun 2018 terdapat 68 pengguna, pada tahun 2019 terdapat 34 pengguna, dan pada tahun 2020 terdapat 81 pengguna. Berdasarkan data tersebut dilihat bahwa dari tahun 2018 dan 2019 mengalami penurunan dan pada tahun 2020 pengguna KB Suntik 3 Bulan mengalami kenaikan.

Beberapa pengguna KB suntik sampai saat ini belum mengetahui efek samping yang akan muncul setelah dilakukan penyuntikan kurang lebih 1 bulan ibu baru menyadari bahwa ada perbedaan yang terjadi dalam dirinya contohnya siklus haid mulai berubah, penambahan/penurunan berat badan, timbulnya jerawat, mual dan muntah, rambut rontok, pusing, dan adanya perdarahan bercak (Gayatri \& Irawaty, 2021; Hyttel et al., 2012). Berdasarkan data wawancara dan survei awal di Puskesmas Bulango Selatan yang dilakukan oleh peneliti kepada 10 responden terhadap Akseptor KB Suntik 3 Bulan, menyatakan bahwa 
diantara responden mengalami gangguan menstruasi, peningkatan berat badan, sakit kepala, dan masih banyak alasan yang diakibatkan oleh KB Suntik 3 Bulan di Puskesmas Bulango Selatan. Urgensi dari penelitian ini yaitu beberapa responden yang belum mengetahui efek samping dari KB suntik 3 bulan. Sehingga peneliti berasumsi bahwa harus diadakannya suatu penelitian yang menyatakan hubungan dari efek samping dengan kecemasan Akseptor.

\section{Metode}

Penelitian ini dilaksanakan di Puskesmas Bulango Selatan Dan waktu penelitian ini dilaksanakan mulai tanggal 15-29 September 2021. Penelitian ini adalah penelitian kuantitatif dengan metode observasional analitik dan dengan pendekatan cross sectional study. Populasi penelitian ini adalah berjumlah 81 akseptor KB suntik 3 Bulan di Puskesmas Bulango Selatan tahun 2020. Sampel dalam penelitian ini adalah seluruh pengguna KB suntik 3 bulan yang berada di Puskesmas Bulango Selatan tahun 2021. Teknik pengumpulan data dilakukan dengan wawancara menggunakan kuesioner dan dianalisis menggunakan uji pearson chi-square dengan bantuan program computer (SPSS).

\section{Hasil}

Efek Samping KB Suntik 3 Bulan

Tabel 1. Efek Samping KB Suntik 3 Bulan

\begin{tabular}{ccc}
\hline Efek Samping & \multicolumn{2}{c}{ Jumlah } \\
\cline { 2 - 3 } & $\mathrm{n}$ & $\%$ \\
\hline Ada & 20 & 26.7 \\
Tidak ada & 55 & 73.3 \\
\hline Jumlah & 75 & 100.0 \\
\hline Sumber : Data & Primer, 2021
\end{tabular}

Berdasarkan tabel, efek samping KB suntik 3 bulan yang dialami akseptor KB Suntik 3 bulan sebanyak 20 responden $(26.7 \%)$ merasakan efek samping dan sebanyak 55 responden $(73.3 \%)$ tidak merasakan efek samping.

Tingkat Kecemasan Akseptor KB Suntik 3 Bulan

Tabel 2. Pemanfaatan Layanan E-Puskesmas di Puskesmas Kota Barat

\begin{tabular}{ccc}
\hline Tingkat Kecemasan & \multicolumn{2}{c}{ Jumlah } \\
\cline { 2 - 3 } & $\mathrm{n}$ & $\%$ \\
\hline Tidak cemas & 6 & 8.0 \\
Cemas ringan & 33 & 44.0 \\
Cemas sedang & 27 & 36.0 \\
Cemas berat & 9 & 12.0 \\
\hline Jumlah & 75 & 100.0 \\
\hline Sumber : Data Primer, 2021
\end{tabular}

Berdasarkan tabel, diperoleh bahwa tingkat kecemasan akseptor KB suntik 3 bulan yang dialami ibu sebanyak 9 responden (12.0\%) yang memiliki tingkat kecemasan yang berat, 
27responden (36.0\%) yang memiliki tingkat kecemasan sedang, 33 responden (44.0\%) yang memiliki tingkat kecemasan ringan dan 6 responden (8.0\%) yang tidak cemas.

Hubungan Efek Samping dan Tingkat Kecemasan Akseptor KB Suntik 3 Bulan

Tabel 3. Hubungan Efek Samping dan Tingkat Kecemasan Akseptor KB Suntik 3 Bulan

\begin{tabular}{|c|c|c|c|c|c|c|c|c|c|c|c|}
\hline \multirow{3}{*}{$\begin{array}{c}\text { Efek } \\
\text { samping }\end{array}$} & \multicolumn{8}{|c|}{ Tingkat kecemasan akseptor KB suntik 3 bulan } & \multicolumn{2}{|c|}{ Jumlah } & \multirow{2}{*}{$\begin{array}{c}p- \\
\text { value }\end{array}$} \\
\hline & \multicolumn{2}{|c|}{$\begin{array}{l}\text { Tidak } \\
\text { cemas }\end{array}$} & \multicolumn{2}{|c|}{$\begin{array}{l}\text { Cemas } \\
\text { ringan }\end{array}$} & \multicolumn{2}{|c|}{$\begin{array}{l}\text { Cemas } \\
\text { sedang }\end{array}$} & \multicolumn{2}{|c|}{ Cemas berat } & & & \\
\hline & $\mathrm{n}$ & $\%$ & $\mathrm{n}$ & $\%$ & $\mathrm{n}$ & $\%$ & $\mathrm{n}$ & $\%$ & $\mathrm{n}$ & $\%$ & \\
\hline Ada & 0 & 0.0 & 3 & 15.0 & 14 & 70.0 & 3 & 15.0 & 20 & 26.7 & 0.001 \\
\hline Tidak ada & 6 & 10.9 & 30 & 54.5 & 13 & 23.6 & 6 & 10.9 & 55 & 73.3 & \\
\hline Jumlah & 6 & 10.9 & 33 & 69.5 & 27 & 93.6 & 9 & 25.9 & 75 & 100.0 & \\
\hline
\end{tabular}

Sumber : Data Primer, 2021

Berdasarkan tabel, diperoleh bahwa dari 75 responden yang paling banyak yaitu responden dengan tidak memiliki efek samping sebanyak 55 responden (73.3\%) dimana responden yang tingkat kecemasan berat sebanyak 6 responden (10.9\%), cemas sedang sebanyak 13 resonden (23.6\%), cemas ringan sebanyak 30 responden (54.5\%) dan yang tidak cemas sebanyak 6 responden $(10.9 \%)$. Kemudian yang paling sedikit yaitu responden dengan memiliki atau ada efek samping sebanyak 20 responden $(26.7 \%)$ dimana responden yang memiliki tingkat kecemasan berat sebanyak 3 responden (15.0\%), cemas sedang sebanyak 14 responden (70.0\%), cemas ringan sebanyak 3 responden (15.0\%) dan yang tidak cemas sebanyak 0 responden $(0.0 \%)$. Hasil uji statistik diperoleh nilai p value sebesar $0.001<\alpha=0,05$ sehingga Ho ditolak. Dengan demikian dapat disimpulkan bahwa terdapat pengaruh antara efek samping dengan tingkat kecemasan akseptor KB suntik 3 bulan.

\section{Pembahasan}

Efek samping kontrasepsi suntik adalah suatu pengaruh atau dampak negatif yang ditimbulkan oleh kontrasepsi suntik. Adapun efek samping yang sering terjadi yaitu gangguan haid, berat badan bertambah, keputihan, dan sakit kepala (Sari et al., 2015). Pemakaian kontrasepsi suntik bulanan maupun tri bulanan mempunyai efek samping utama yaitu perubahan berat badan (Kurniasari et al., 2020). Faktor yang mempengaruhi perubahan berat badan akseptor KB suntik adalah adanya hormon Progesteron yang kuat sehingga merangsang nafsu makan yang ada di Hipotalamus dengan adanya nafsu makan yang lebih banyak, tubuh akan kelebihan zat gizi (Febriani \& Ramayanti, 2020; Harahap, 2019; Mustopa, 2019). Kelebihan zat gizi oleh Progesteron dirubah, menjadi lemak dan disimpan dibawah kulit (Saraswati \& Dieny, 2012). Kelebihan gizi dalam artian pola makan yang tidak tepat dapat meningkatkan risiko kejadian Hipertensi (Kadir, 2019). Perubahan berat badan ini akibat adanya penumpukan lemak yang berlebihan hasil sintesa dari karbohidrat menjadi lemak. 
Banyak akseptor kontrasepsi, terutama akseptor KB suntik 3 bulan yang merasa cemas mengenai efek samping yang mungkin terjadi, seperti peningkatan berat badan, gangguan haid, sakit kepala dan lain-lain (Noviyanti, 2017). Adapun efek samping lain yang ditimbulkan berdasarkan hasil yang didapat oleh peneliti melalui kuesioner bahwa semakin lama ibu menggunakan alat kontrasepsi $\mathrm{KB}$ suntik 3 bulan maka akan berpengaruh terhadap siklus menstruasinya.

Kecemasan adalah keadaan emosi tanpa objek tertentu (Stuward, 2015). Kecemasan dipicu oleh hal yang tidak diketahui dan menyertai semua penglaman baru, seperti masuk sekolah, memulai pekerjaan baru atau melahirkan anak. Karakteristik kecemasan ini yang membedakan dari rasa takut. Sedangkan tidak cemas adalah kondisi dimana seseorang tidak mengalami suatu reaksi atau respon terhadap kecemasan terutama pada akseptor KB suntik 3 bulan. Menurut penelitian yang dilakukan dijabotabek terhadap 208 orang akseptor KB suntik 3 bulan, sebanyak 76\% mengaku cemas ketika mengalami spotting (Septianingrum et al., 2018). Kondisi ini dapat mengakibatkan kecemasan pada ibu sehingga sering menimbulkan masalah psikologis misalnya ibu menjadi lebih sensitif perasaannya, mudah marah dan emosi menjadi tidak stabil dan berdampak pada kehidupan rumah tangganya.

Berdasarkan hasil uji Pearson Chi-Square diperoleh nilai p value sebesar $0.001<\alpha=0,05$ sehingga $\mathrm{H}_{0}$ ditolak. Dengan demikian dapat disimpulkan bahwa terdapat pengaruh antara efek samping dengan tingkat kecemasan akseptor KB suntik 3 bulan. Dari hasil penelitian tersebut dapat dijelaskan bahwa yang mendominasi yaitu ibu yang tidak memiliki efek samping dan tergolong tingkat kecemasannya ringan. Kecemasan ringan yang ada pada akseptor KB suntik 3 bulan disebabkan karena kebanyakan akseptor KB suntik 3 bulan sudah mengetahui tentang efek samping KB suntik dari berbagai sumber salah satunya dari penyuluhan tenaga kesehatan yang ada di puskesmas. Apabila dikaitkan dengan kecemasan, ketika seseorang mengalami hambatan dalam keinginannya, dalam hal ini penggunaan alat kontrasepsi, maka akan timbul perasaanperasaan tertekan yang muncul dalam kesadaran.

Penelitian ini sejalan dengan penelitian tentang hubungan antara efek samping KB dengan skor kecemasan akseptor KB suntik 3 bulan dipuskesmas Kebonsari Mediun yang menjelaskan agar kecemasan akseptor KB berkurang sebaiknya akseptor KB mendapatkan konseling (Ratrianto, 2015). Konseling Keluarga Berencana (KB) bertujuan membantu klien membuat pilihan metode kontrasepsi yang tepat bagi diri sendiri dan mendapatkan solusi berbagai masalah kesehatan reproduksi (Prawitasari et al., 2018).

\section{Kesimpulan}

Akseptor KB suntik 3 bulan di Puskesmas Bulango Selatan paling banyak tidak merasakan efek samping yaitu sebanyak 55 responden (73.3\%) sedangkan yang merasakan efek samping sebanyak 20 responden (26.7\%).Tingkat kecemasan akseptor KB suntik 3 bulan di Puskesmas Bulango Selatan yang paling mendominasi yaitu ibu dengan cemas ringan sebanyak 33 responden $(44.0 \%)$ sedangkan yang paling sedikit yaitu ibu dengan tidak cemas sebanyak 6 responden $(8.0 \%)$. Terdapat hubungan antara efek samping dengan tingkat kecemasan akseptor 
KB suntik 3 bulan di Puskemas Bulango Selatan dengan nilai p-value sebesar 0.001, sehingga disarankan agar ibu lebih mengetahui informasi tentang alat kontrasepsi KB suntik 3 bulan guna dalam menekan jumlah pertumbuhan penduduk dan berperan penting dalam program KB.

\section{Referensi}

Febriani, R., \& Ramayanti, I. (2020). Analisis Perubahan Berat Badan pada Pemakaian KB Suntik Depo Medroksi Progesteron Asetat (DMPA). Jurnal 'Aisyiyah Medika, 5(1). https://doi.org/10.36729/jam.v5i1.317

Gayatri, M., \& Irawaty, D. K. (2021). Side Effects of Injectable and Oral Contraceptive and Unintended Pregnancy Among Reproductive Women In Indonesia. Jurnal Biometrika Dan Kependudukan, 10(2). https://doi.org/10.20473/jbk.v10i2.2021.162-170

Harahap, R. (2019). Pengaruh Kb Suntik Depo Medroksi Progesteron Asetat (DMPA) Terhadap Peningkatan Berat Badan Ibu Di Klinik Bersalin Sahara Padangsidimpuan Tahun 2014. Jurnal Ilmiah PANNMED (Pharmacist, Analyst, Nurse, Nutrition, Midwivery, Environment, Dentist), 9(3). https://doi.org/10.36911/pannmed.v9i3.203

Hyttel, M., Rasanathan, J. J. K., Tellier, M., \& Taremwa, W. (2012). Use of injectable hormonal contraceptives: Diverging perspectives of women and men, service providers and policymakers in Uganda. Reproductive Health Matters, 20(40). https://doi.org/10.1016/S0968-8080(12)40654-1

Kadir, S. (2019). Pola Makan dan Kejadian Hipertensi. Jambura Health and Sport Journal, 1(2). https://doi.org/10.37311/jhsj.v1i2.2469

Kemenkes RI. (2018). Hasil Riset Kesehatan Dasar Tahun 2018. Kementrian Kesehatan RI, 53(9).

Kurniasari, D., Susilawati, S., \& Fenniokha, N. G. (2020). Pengaruh Kontrasepsi Suntik 3 Bulan terhadap Kenaikan Berat Badan Ibu di Puskesmas Gedong Air Kota Bandar Lampung Tahun 2020. Jurnal Medika Malahayati, 4(4). https://doi.org/10.33024/jmm.v4i4.3330

Kusumawardani, P. A., \& Machfudloh, H. (2021). Efek Samping KB Suntik Kombinasi (Spotting) dengan Kelangsungan Akseptor KB Suntik Kombinasi. JI-KES (Jurnal Ilmu Kesehatan), 5(1). https://doi.org/10.33006/ji-kes.v5i1.227

Mustopa, F. L. (2019). Analisis Perbandingan Kenaikan Berat Badan Ibu Yang Menggunakan KB Suntik Cyclofem dan Depo Medroksi Progesteron Asetat (DMPA) di Puskesmas Pasar Terusan Kabupaten Batanghari Jambi. Jurnal Ilmu Kedokteran Dan Kesehatan, 5(3). https://doi.org/10.33024/hjk.v9i4.946

Noviyanti, N. I. (2017). Hubungan Antara Efek Samping dengan Skor Kecemasan Aksebtor KB Suntik 3 Bulan di RS TK II Pelamonia Makassar Tahun 2017. JURNAL KESEHATAN DELIMA PELAMONIA, 1(2). https://doi.org/10.37337/jkdp.v1i2.43

Prawitasari, S., Sangun, D. I. E., Rahman, M. N., \& Emilia, O. (2018). Client Satisfaction After Family Planning Counseling by Trained Medical Students. Jurnal Kesehatan Reproduksi, 4(3). https://doi.org/10.22146/jkr.36199 
Rahmidini, A., Supiyani, T., \& Akbar, A. (2020). Upaya Peningkatan Partisipasi PUS dalam Keluarga Berencana di Dusun Gunung Kawung Desa Cikunir Kecamatan Singaparna Kabupaten Tasikmalaya Tahun 2019. Jurnal Abdimas Kesehatan Tasikmalaya, 1(02). https://doi.org/10.48186/abdimas.v1i02.285

Ratrianto, W. E. (2015). Hubungan Antara Efek Samping KB Dengan Skor Kecemasan Akseptor Kb Suntik 3 Bulan Di Puskesmas Kebonsari Madiun [Universitas Muhammadiyah Surakarta]. http://eprints.ums.ac.id/

Saraswati, I., \& Dieny, F. F. (2012). Perbedaan Karakteristik Usia, Asupan Makanan, Aktivitas Fisik, Tingkat Sosial Ekonomi dan Pengetahuan Gizi pada Wanita Dewasa dengan Kelebihan Berat Badan Antara di Desa dan Kota. Journal of Nutrition College, 1(1). https://doi.org/10.14710/jnc.v1i1.726

Sari, S., Suherni, S., \& Purnamaningrum, Y. (2015). Gambaran Efek Samping Kontrasepsi Suntik Pada Akseptor KB Suntik. Jurnal Kesehatan Ibu Dan Anak, 8(2).

Septianingrum, Y., Wardani, E. M., \& Kartini, Y. (2018). Faktor-Faktor yang Mempengaruhi Tingginya Akseptor KB Suntik 3 Bulan. Jurnal Ners Dan Kebidanan (Journal of Ners and Midwifery), 5(1). https://doi.org/10.26699/jnk.v5i1.art.p015-019

Sinurat, L., \& Pinem, M. (2017). Keadaan Gerakan Keluarga Berencana Di Desa Parlondu Kecamatan Pangururan Kabupaten Samosir. JPPUMA: Jurnal Ilmu Pemerintahan Dan Sosial Politik Universitas Medan Area, 5(2). https://doi.org/10.31289/jppuma.v5i2.1249

Stuward, S. (2015). Buku Saku Keperawatan. EGC. 